\title{
The gut microbiome in psychopharmacology and psychiatry
}

\author{
John F. Cryan ${ }^{1,2} \cdot$ Harriet de Wit ${ }^{3}$ \\ Published online: 6 June 2019 \\ (C) Springer-Verlag GmbH Germany, part of Springer Nature 2019
}

The last decade has seen an explosion of research implicating the trillions of symbiotic bacteria (microbiota) and their genetic material (microbiome) within the gut as playing a key role in programming different aspects of host physiology (Gilbert et al. 2018). Indeed, the human gut microbiome has been shown to influence many aspects of host health, including brain health (Bastiaanssen et al. 2019). Several modes of interaction between the gut and the brain have been discovered, including the synthesis of metabolites and neurotransmitters, activation of the vagus nerve, and activation of the immune system (Cryan et al. 2019a). A growing body of work is implicating the microbiome in a variety of psychological processes and neuropsychiatric disorders. These include mood and anxiety disorders, neurodevelopmental disorders such as autism spectrum disorder and schizophrenia, and even neurodegenerative disorders such as Alzheimer's and Parkinson's diseases (Cryan et al. 2019a). In addition, there is increasing emphasis on the bidirectional interaction between drugs and the gut microbiome (Clarke et al. 2019). An expanding body of evidence supports the notion that microbes can metabolize drugs and, vice versa, drugs can modify the gut microbiota composition.

With this in mind, it was timely to have a Special Issue of Psychopharmacology dedicated to the microbiome and how it intersects with the disciplines of psychopharmacology and psychiatry. The lead review summarizes what is known about the effects of different classes of psychotropics including antipsychotics, antidepressants, antianxiety drugs, anticonvulsants/mood stabilizers, opioid analgesics, drugs of abuse, alcohol, nicotine, and xanthines on the

John F. Cryan

j.cryan@ucc.ie

1 APC Microbiome Ireland, University College Cork, Cork, Ireland

2 Department of Anatomy and Neuroscience, University College Cork, Cork, Ireland

3 Department of Psychiatry and Behavioral Neuroscience, University of Chicago, Chicago, IL, USA microbiome (Cussotto et al. 2019a). The varying effects of these widely used medications on microorganisms are becoming apparent from both in vivo and in vitro studies as exemplified by the primary research paper on this topic (Cussotto et al. 2019b) focused on the effects of a number of psychotropic medications on microbiota composition. Such studies reinforce the need to consider the host microbiome during drug discovery and development and its relative contribution to the efficacy and side effect profile of psychotropic medications.

Depression has been one of the disorders in psychiatry where there is significant accumulating evidence for a role of the microbiome emerging from human (Valles-Colomer et al. 2019) and animal studies (Peirera et al. 2019). In this regard, Gondolia and colleagues (Gondalia et al. 2019) review the accumulating evidence for the gut microbiota in bipolar disorder. At an experimental level, Tillmann et al. (2019) show an altered fecal microbiota composition in the Flinders Sensitive Line rat model of depression, whereas Heym and colleagues explore the role of microbiota and inflammation in self-judgment and empathy in a small cohort $(n=40)$ of individuals with depression (Heym et al. 2019).

Regarding schizophrenia, Jaskiw et al. (2019) investigate how metabolites from the gut microbiota may modify circuits involved in neurodevelopment. Focusing on treatments, Skonieczna-Zydecka et al. (2018) review the potential of atypical antipsychotics to alter gut microbiome composition.

There is a growing emphasis on the potential role for the gut microbiome in substance use disorders and this is reviewed by Meckel and Kiraly (Meckel and Kiraly 2019). This is supported by a research paper focusing on the impact of alcohol-induced changes on the gut microbiome and metabolome in rhesus macaques (Zhang et al. 2019). Moreover, the relationship between dopamine mechanisms and the microbiome is reviewed (GonzalezArancibia et al. 2019), whereas Ruusunen and colleagues focus on the role of the gut microbiome in anorexia nervosa (Ruusunen et al. 2019). 
The perinatal period is one of the most sensitive times for which microbiome can affect brain and behavior (Codagnone et al. 2019). In this regard, Slykerman et al. (2019) investigates the impact of exposure to antibiotics in the first 24 months of life on neurocognitive outcomes at 11 years of age. On the other hand, Gao and colleagues (Gao et al. 2019) present one of the few brain imaging studies published to date investigating the relationship between the gut microbiome and brain functional connectivity in infants. Tandem animal studies are investigating the relationship between early life stress and gut barrier function in rats (Rincel et al. 2019). At the other extreme of life, there is a growing realization of the role of the microbiome in aging (Cryan et al. 2019b) and Komanduri et al. (2019) review the available data on the microbiome and cognitive aging.

One of the big challenges for the field moving forward is understanding the mechanisms of microbiota to brain communication. A number of papers focus on these in the Special Issue. Aresti Sanz and El Aidy (2019) zone in on gut neuropeptides emphasizing their activity locally in the gut and on neuroimmune function in the brain. On the other hand, the relationship between host genetics and microbiota with an interesting focus on fecal microRNAs is investigated experimentally (Horne et al. 2019). Finally, Smith and colleagues (Smith et al. 2019) seek to identify and characterize a bacterial-derived lipid that may contribute to the behavioral and physiological effects of a Mycobacterium vaccae, a soilderived bacterium with immunoregulatory and stress resilience properties.

It is clear that there has been an explosion of research implicating the microbiota in psychopharmacology and psychiatry. However, it is still very much early days and the full implications of the extent the microbiota can translate into therapeutic hope for brain diseases remains to be fully appreciated.

\section{References}

Aresti Sanz J, and El Aidy S. (2019). Microbiota and gut neuropeptides: a dual action of antimicrobial activity and neuroimmune response. Psychopharmacology In Press https://doi.org/10.1007/s00213-01905224-0

Bastiaanssen TFS, Cowan CSM, Claesson MJ, Dinan TG, Cryan JF (2019) Making sense of... the microbiome in psychiatry. Int J Neuropsychopharmacol 22:37-52

Clarke G, Sandhu KV, Griffin BT, Dinan TG, Cryan JF, Hyland NP (2019) Gut reactions: breaking down xenobiotic-microbiome interactions. Pharmacol Rev 71:198-224

Codagnone MG, Spichak S, O'Mahony SM, O'Leary OF, Clarke G, Stanton C, Dinan TG, Cryan JF (2019) Programming bugs: microbiota and the developmental origins of brain health and disease. Biol Psychiatry 85:150-163

Cryan et al (2019a) The microbiota-gut-brain axis. Physiological Reviews In Press

Cryan JF, Boehme M, Dinan TG (2019b) Is the fountain of youth in the gut microbiome? J Physiol 597:2323-2324

Cussotto S, Clarke G, Dinan TG, and Cryan JF (2019a). Psychotropics and the microbiome: a chamber of secrets. Psychopharmacology In Press https://doi.org/10.1007/s00213-019-5185-8

Cussotto S, Strain CR, Fouhy F, Strain RG, Peterson VL, Clarke G, Stanton C, Dinan TG, and Cryan JF (2019b). Differential effects of psychotropic drugs on microbiome composition and gastrointestinal function. Psychopharmacology In Press https://doi.org/10. 1007/s00213-018-5006-5

Gao W, Salzwedel AP, Carlson AL, Xia K, Azcarate-Peril MA, Styner MA, Thompson AL, Geng X, Goldman BD, Gilmore JH, et al. (2019). Gut microbiome and brain functional connectivity in infants-a preliminary study focusing on the amygdala. Psychopharmacology (Berl). In Press https://doi.org/10.1007/ s00213-018-5161-8

Gilbert JA, Blaser MJ, Caporaso JG, Jansson JK, Lynch SV, Knight R (2018) Current understanding of the human microbiome. Nat Med 24:392-400

Gondalia S, Parkinson L, Stough C, and Scholey A (2019). Gut microbiota and bipolar disorder: a review of mechanisms and potential targets for adjunctive therapy. Psychopharmacology In Press https:// doi.org/10.1007/s00213-019-05248-6

Gonzalez-Arancibia C, Urrutia-Pinones J, Illanes-Gonzalez J, MartinezPinto J, Sotomayor-Zarate R, Julio-Pieper M, and Bravo JA (2019). Do your gut microbes affect your brain dopamine? Psychopharmacology (Berl). In Press https://doi.org/10.1007/ s00213-019-05265-5

Heym N, Heasman BC, Hunter K, Blanco SR, Wang GY, Siegert R, Cleare A, Gibson GR, Kumari V, and Sumich AL (2019). The role of microbiota and inflammation in self-judgement and empathy: implications for understanding the brain-gut-microbiome axis in depression. Psychopharmacology In Press https://doi.org/10.1007/ s00213-019-05230-2.

Horne R, St Pierre J, Odeh S, Surette M, and Foster JA (2019). Microbe and host interaction in gastrointestinal homeostasis. Psychopharmacology In Presshttps://doi.org/10.1007/s00213-01905218-y.

Jaskiw et al (2019) The phenolic interactome and gut microbiota: potential and challenges for biomarker development in schizophrenia and autism Psychopharmacology (Berl). In Press

Komanduri M, Gondalia S, Scholey A, and Stough, C. (2019). The microbiome and cognitive aging: a review of mechanisms. Psychopharmacology (Berl). In Press https://doi.org/10.1007/ s00213-019-05231-1

Meckel KR, and Kiraly DD (2019). A potential role for the gut microbiome in substance use disorders. Psychopharmacology (Berl). In Press https://doi.org/10.1007/s00213-019-05232-0

Cruz-Pereira, et al., (2019) Depression's unholy trinity - dysregulated stress, immunity and the microbiome. Annual Rev. Psychology In Press

Rincel et al (2019) Pharmacological restoration of gut barrier function in stressed neonates partially reverses long-term alterations associated with maternal separation Psychopharmacology (Berl). In Press https://doi.org/10.1007/s00213-019-05252-w

Ruusunen A, Rocks T, Jacka F, and Loughman, A. (2019). The gut microbiome in anorexia nervosa: relevance for nutritional 
rehabilitation. Psychopharmacology In Press https://doi.org/10. 1007/s00213-018-5159-2

Skonieczna-Zydecka K, Loniewski I, Misera A, Stachowska E, Maciejewska D, Marlicz W, and Galling B (2018). Secondgeneration antipsychotics and metabolism alterations: a systematic review of the role of the gut microbiome. Psychopharmacology (Berl). In Press https://doi.org/10.1007/s00213-018-5102-6

Slykerman RF, Coomarasamy C, Wickens, K, Thompson JMD, Stanley TV, Barthow C, Kang J, Crane J, and Mitchell EA (2019). Exposure to antibiotics in the first 24 months of life and neurocognitive outcomes at 11 years of age. Psychopharmacology In Press https://doi. org/10.1007/s00213-019-05216-0

Smith et al., (2019) Identification and characterization of a novel antiinflammatory lipid isolated from Mycobacterium vaccae, a soilderived bacterium with immunoregulatory and stress resilience properties Psychopharmacology (Berl). In Press https://doi.org/10. 1007/s00213-019-05253-9

Tillmann S, Abildgaard A, Winther G, and Wegener G (2019). Altered fecal microbiota composition in the Flinders sensitive line rat model of depression. Psychopharmacology (Berl). In Press https://doi.org/ 10.1007/s00213-018-5094-2

Valles-Colomer M, Falony G, Darzi Y, Tigchelaar EF, Wang J, Tito RY, Schiweck C, Kurilshikov A, Joossens M, Wijmenga C, Claes S, van Oudenhove L, Zhernakova A, Vieira-Silva S, Raes J (2019) The neuroactive potential of the human gut microbiota in quality of life and depression. Nat Microbiol 4:623-632

Zhang X, Yasuda K, Gilmore RA, Westmoreland SV, Platt DM, Miller GM, Vallender EJ. (2019) Alcohol-induced changes in the gut microbiome and metabolome of rhesus macaques. Psychopharmacology. doi: https://doi.org/10.1007/s00213-01905217-z

Publisher's note Springer Nature remains neutral with regard to jurisdictional claims in published maps and institutional affiliations. 